\title{
ГЕНОМНАЯ АРХИТЕКТУРА РОССИЙСКОЙ ПОПУЛЯЦИИ ЗААНЕНСКИХ КОЗ В АСПЕКТЕ ГЕНОФОНДА ПОРОДЫ ИЗ ПЯТИ СТРАН МИРА*
}

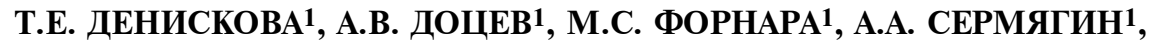 \\ H. REYER ${ }^{2}$, K. WIMMERS ${ }^{2}$, G. BREM1, 3, H.A. 3ИНOBЬEBA ${ }^{1}$
}

\begin{abstract}
Зааненская порода коз ценится за высокую молочную продуктивность и хорошие адаптационные качества, которые способствовали ее широкому распространению в мире за пределами Швейцарии. В России зааненская порода официально рекомендована к разведению и имеет племенной статус. Разведение в локальных условиях окружающей среды, а также региональные особенности используемых селекционных стратегий могут приводить к существенному изменению аллелофонда пород, в связи с чем актуально проведение геномных исследований национальных популяций мировых пород с целью установления их современного генетического статуса. В настоящей работе впервые представлены данные полногеномного анализа российской популяции коз зааненской породы, для которой была проведена сравнительная оценка с оригинальным (Швейцария) и мировым генофондом зааненской породы, представленным четырьмя странами. Нашей целью было рассмотрение генетического разнообразия и установление структуры российской популяции зааненской породы в аспекте генофонда коз этой породы из пяти различных стран (Швейцария, Франция, Италия, Аргентина и Танзания), полногеномные SNP-профили которых были получены из базы данных проекта AdaptMap. Исследования проводили на козах (Capra hircus) зааненской породы $(n=21$, RUS), разводимых в одном из племенных репродукторов на территории Российской Федерации, в 2019-2020 годах. ДНК выделяли из отобранных фрагментов ушной раковины с помощью наборов ДНК-Экстран-2 (ЗАО «Синтол», Россия). Генотипирование осуществляли с использованием ДНК-чипа GoatSNP50 BeadChip («Illumina, Inc.», США), содержащего 53347 SNPs и обеспечивающего покрытие среднего интервала между SNP в размере 40 кб. Для оценки генетического разнообразия и сравнительного анализа российской популяции коз с генофондом коз этой породы из пяти различных стран использовали SNPпрофили зааненских коз, разводимых в Швейцарии (SWI, $n=38)$, Италии (ITA, $n=22)$, Франции (FRA, $n=55)$, Аргентине (ARG, $n=11)$ и Танзании (TNZ, $n=8)$, которые были получены из публично доступного хранилища цифровых данных Dryad и сгенерированы в рамках проекта AdaptМap. В качестве образца оригинального генофонда была выбрана швейцарская популяция зааненской породы. Биоинформационную обработку и визуализацию данных полногеномного генотипирования проводили в программах PLINK 1.90, Admixture 1.3, SplitsTree 4.14.5, в пакетаx $R$ «diveRsity» и «рорhelper». Наблюдаемая гетерозиготность варьировала от 0,381 у SWI до 0,423 у FRA и была высокой у RUS $($ Ho $=0,418)$. В популяциях SWI, ITA, FRA значения коэффициента инбридинга оказались близки к нулю; у RUS, ARG и TNZ был отмечен дефицит гетерозигот - соответственно 1,$5 ; 8,9$ и 6,0 \%. Аллельное разнообразие было максимальным у ARG, RUS и FRA $(\mathrm{Ar} \geq 1,979)$ и минимальным - y SWI $(\mathrm{Ar}=1,934)$. Анализ главных компонент и структура филогенетического дерева показали четкую дифференциацию между национальными и оригинальной популяциями зааненской породы. Анализ популяционной структуры подтвердил сохранение генетической составляющей кластера SWI у коз группы RUS. У RUS наблюдались наименьшие генетические дистанции с FRA $\left(\mathrm{F}_{\mathrm{ST}}=0,02 ; \mathrm{R}_{\mathrm{ST}}=0,189\right)$ и ITA $\left(\mathrm{F}_{\mathrm{ST}}=0,023\right.$; $\left.R_{\mathrm{ST}}=0,215\right)$; наиболышая дифференциация RUS была выявлена с $T N Z\left(F_{S T}=0,054 ; R_{S T}=0,311\right)$ и SWI $\left(F_{S T}=0,06 ; R_{S T}=0,276\right)$. Таким образом, различные стратегии селекции привели к генетическим различиям между национальными популяциями коз зааненской породы, при этом российская популяция коз сохраняет в себе геномные компоненты исходного генофонда.
\end{abstract}

Ключевые слова: зааненская порода, домашние козы, SNP-маркеры, ДНК-чипы, генетическое разнообразие, AdaptMap.

За историю существования домашнего козоводства в мире было создано более 50 пород коз молочного направления продуктивности (1), среди которых наиболее популярна зааненская порода. Свое название она получила от швейцарской долины Зааненталь, где была выведена методом длительной народной селекции в середине XIX века $(2,3)$. Среди коз заа-

\footnotetext{
* При проведении исследований использовано оборудование ЦКП «Биоресурсы и биоинженерия сельскохозяйственных животных» ФГБНУ ФНЦ животноводства - ВИЖ им. академика Л.К. Эрнста. Исследование проведено при поддержке РФФИ, проект № 18-316-20006.
} 
ненская порода - своеобразный аналог голштинской породы коров, характеризующийся высокой молочной продуктивностью (от 300 до 2000 кг за 150-300 сут лактации) (3). Козы этой породы легко акклиматизируются к различным условиям содержания и кормления без существенной потери молочности. Они были импортированы из Швейцарии в большинство стран Европы (3, 4), Северной (5) и Южной Америки (6) Австралии (7), Азии (8) и Африки (9), где использование их ценного генофонда значительно преобразовало национальную молочную индустрию.

Согласно официальным данным (10), племенное молочное козоводство в России представлено четырьмя иностранными породами: альпийская (с 2015 года), зааненская (с 1993 года), мурсиано гранадина (Murciano-Granadina) (с 2019 года) и нубиан (Nubian) (с 2018 года). Зааненская порода, по данным на 2018 год, была наиболее распространена (11). Племенное поголовье коз зааненской породы было сосредоточено на трех племенных заводах, в шести племенных репродукторах и одном генофондном хозяйстве и составляло 12,3 тыс. гол. Удой по стаду варьировал от 822 кг за 305 сут лактации в племрепродукторе ООО «КХ «Русь-1» (Ставропольский край, Буденновский p-н, с. Покойное) до 961 кг за 305 сут лактации в племрепродукторе ООО «Березка» (Курская обл., Курский р-н, д. Петровское) (4).

Помимо использования чистопородных зааненских коз для производства молочной продукции, перспективно их скрещивание с местными популяциями коз $(1,12)$. Так, козлы-производители зааненской породы высококлассный улучшающий материал, позволяющий за короткие сроки преобразовать беспородные низкопродуктивные группы коз (с удоем 200250 кг за 305 сут лактации) в надежных продуцентов молока с удоем до 663 кг за 305 сут лактации $(1,12)$.

Геномные исследования домашних коз несколько отставали от других видов сельскохозяйственных животных (13). Только в 2013 году три крупные научные группы, ведущие проекты по поиску SNPs (single nucleotide polymorphism), объединились в Международный консорциум по геномике коз (International Goat Genome Consortium, IGGC) с целью создания ДНК-чипа (14). В результате отбора 53347 SNPs вошли в финальный состав чипа Goat SNP50 BeadChip («Illumina, Inc.», США).

Разработка ДНК-чипа обусловила повышенный интерес к исследованиям особенностей организации генома домашних коз. Например, L. Nicoloso c coaвт. (15) исследовали генетическое разнообразие 14 итальянских пород коз на основе данных полногеномного сканирования. K. Mdladla c соавт. (16) продемонстрировали прикладную значимость полногеномного SNP анализа в исследованиях аборигенных пород коз ЮАР. Применив Goat SNP50 BeadChip, S.A. Rahmatalla с соавт. (17) идентифицировали гены, ассоциированные с ростом, развитием костей и формированием иммунной системы у суданских коз. L.F. Brito с соавт. (18) изучили генетическое разнообразие у более чем 1000 гол. из девяти популярных коммерческих пород коз.

Многочисленные исследования привели к генерации SNP-профилей пород коз разных стран во всем мире (3171 коз из 117 популяций), собранных в базу данных в рамках проекта AdaptMap $(19,20)$, которая была использована для выявления регионов гомозиготности (20), установления исторических путей миграции коз (21) и поиска локусов, находящихся под давлением селекции (22). Кроме того, создание публично доступных баз данных SNP-профилей позволяет изучать породы, импортированные в различные страны, с целью оценки их расхождения или сходства с ориги- 
нальным генофондом.

В настоящей работе впервые представлены данные полногеномного анализа российской популяции коз зааненской породы, для которой была проведена сравнительная оценка с оригинальным (Швейцария) и мировым генофондом зааненской породы, представленным четырьмя странами.

Нашей целью было рассмотрение генетического разнообразия и установление структуры российской популяции зааненской породы в аспекте генофонда коз этой породы из пяти различных стран (Швейцария, Франция, Италия, Аргентина и Танзания), полногеномные SNP-профили которых были получены из базы данных проекта AdaptMap.

Методика. Исследования проводили на козах (Capra hircus) зааненской породы ( $n=21$, RUS), разводимых в одном из племенных репродукторов на территории Российской Федерации, в 2019-2020 годах. ДНК выделяли из отобранных фрагментов ушной раковины с помощью наборов ДНК-Экстран-2 (ЗАО «Синтол», Россия). Генотипирование осуществляли с использованием ДНК-чипа GoatSNP50 BeadChip («Illumina, Inc.», США), содержащего 53347 SNPs и обеспечивающего покрытие среднего интервала между SNP в размере $40 \mathrm{~kb}$ (14). Чтение ДНК-чипов проводили на приборе iScan Reader («Illumina, Inc.», США), по завершении необработанные данные загружали в программу GenomeStudio 2.0 («Illumina, Inc.», США) для предварительного анализа. Для параметров, характеризующих качество чтения (GenCall, GC) и кластеризацию SNPмаркеров (GenTrain, GT), были установлены предельные допустимые значения 0,5 (23). В программе PLINK 1.90 (24) для использования в последующих расчетах отбирали SNP-маркеры, имеющие частоту минорного аллеля (MAF) более $5 \%$, не отклоняющиеся от равновесия Харди-Вайнберга при $\mathrm{p}<10^{-6}$, находящиеся в равновесии по сцеплению и расположенные только на аутосомах.

Для оценки генетического разнообразия и сравнительного анализа российской популяции коз с мировым генофондом использовали SNP-профили зааненских коз, разводимых в Швейцарии (SWI, $n=38$ ), Италии (ITA, $n=22$ ), Франции (FRA, $n=55$ ), Аргентине (ARG, $n=11$ ) и Танзании (TNZ, $n=8)$, которые были получены из публично доступного хранилища цифровых данных Dryad (25) и сгенерированы в рамках проекта AdaptMap (http://www.goatadaptmap.org/) (20, 21). В качестве образца оригинального генофонда была выбрана швейцарская популяция зааненской породы.

Наблюдаемая $\left(\mathrm{H}_{\mathrm{o}}\right)$ гетерозиготность, несмещенная ожидаемая гетерозиготность $\left(\mathrm{uH}_{\mathrm{e}}\right)$, аллельное разнообразие $(\mathrm{Ar})$, коэффициент инбридинга Fis (с доверительным интервалом 95 \%), попарные значения показателей $\mathrm{F}_{\mathrm{ST}}(26)$ и $\mathrm{R}_{\mathrm{ST}}$ (дистанция Рейнольдса) (27) были рассчитаны в R пакете diveRsity (28). Анализ главных компонент (principal component analysis, PCA) выполняли в программе PLINK 1.9 с последующим построением графика в R пакете ggplot2 (29). Матрица попарных значений F была визуализирована в виде групповой генетической сети Neighbor Net в программе SplitsTree 4.

Популяционная структура и генетическая однородность российской и других групп зааненских коз были установлены в программе Admixture 1.3 (31) с графическим представлением с помощью R пакета pophelper (32). 14.5 (30). Наиболее вероятное число предковых кластеров (K) определяли с помощью расчета значений ошибки кросс-валидации (CV error) для K от 1 до 7 в программе Admixture 1.3.

Биоинформационную обработку данных и работу с рисунками 
(графиками) проводили с помощью программной среды R Project for Statistical Computing (33).

Результаты. Наблюдаемая гетерозитность варьировала от 0,381 у SWI до 0,423 у FRA (табл. 1). Значение показателя $\mathrm{H}_{\mathrm{o}} \mathrm{y}$ RUS $(0,418)$ было ранжировано вторым вслед за максимальным. У трех популяций (SWI, ITA, FRA) коэффициент инбридинга оказался несущественен, что, вероятно, свидетельствует о состоянии, близком к генетическому равновесию. В группе RUS был отмечен небольшой дефицит гетерозигот $(1,5$ \%). Группы ARG и TNZ характеризовались более значительным превышением числа гомозигот над гетерозиготами - соответственно 8,9 и 6,0 \%.

1. Характеристика генетического разнообразия российской и пяти национальных популяций коз (Capra hircus) зааненской породы, оцененного с использованием ДНК-чипа GoatSNP50 BeadChip (2019-2020 годы)

\begin{tabular}{l|c|c|c|c|c}
\hline \multicolumn{1}{c}{ Группа } & $n$ & $\mathrm{H}_{\mathrm{o}}$ & $\mathrm{uH}_{\mathrm{e}}$ & $\mathrm{uF}_{\mathrm{is}}$ & $\mathrm{Ar}$ \\
\hline RUS & 21 & 0,418 & 0,424 & $0,015(0,013 ; 0,017)$ & 1,979 \\
SWI & 38 & 0,381 & 0,380 & $-0,002(-0,003 ;-0,001)$ & 1,934 \\
ITA & 22 & 0,417 & 0,418 & $0,002(0 ; 0,004)$ & 1,975 \\
FRA & 55 & 0,423 & 0,422 & $-0,002(-0,003 ;-0,001)$ & 1,979 \\
ARG & 11 & 0,386 & 0,426 & $0,089(0,086 ; 0,092)$ & 1,980 \\
TNZ & 8 & 0,388 & 0,414 & $0,06(0,057 ; 0,063)$ & 1,970
\end{tabular}

П р и м е ч а н и е. $n-$ число особей в выборке, гол.; $\mathrm{H}_{\mathrm{o}}-$ наблюдаемая гетерозиготность, $\mathrm{uH}_{\mathrm{e}}-$ несмещенная ожидаемая гетерозиготность, $\mathrm{uF}_{\text {is }}$ - коэффициент инбридинга, $\mathrm{Ar}$ - рарифицированное аллельное разнообразие. В скобках приведен размах изменчивости $\mathrm{F}_{\text {is }}$ при доверительном интервале $95 \%$. Ошибка средней арифметической для показателей $\mathrm{H}_{\mathrm{o}}$, uH $\mathrm{H}_{\mathrm{e}}$ и $\mathrm{Ar}$ составляет $\pm 0,001$. Группы коз зааненской породы: RUS - российская, SWI - швейцарская, ITA - итальянская, FRA - французская, ARG аргентинская, TNZ - танзанийская.

Наибольшее аллельное разнообразие было выявлено у популяций ARG $(\operatorname{Ar}=1,980)$, RUS $(\operatorname{Ar}=1,979)$ и FRA $(\operatorname{Ar}=1,979)$. У группы SWI оно оказалось минимальным $(\mathrm{Ar}=1,934)$.

Анализ главных компонент (рис. 1) продемонстрировал, что первая главная компонента, отвечающая за 7,76 \% генетической изменчивости, обособляла группу SWI от остальных пяти популяций, включая RUS. Вторая главная компонента, соответствующая 4,28 \% генетической вариабельности, отделяла SWI, ITA и частично FRA от популяций RUS (некоторые представители располагались практически на оси), ARG и TNZ (располагались в самом отдаленном секторе РСА-плота).

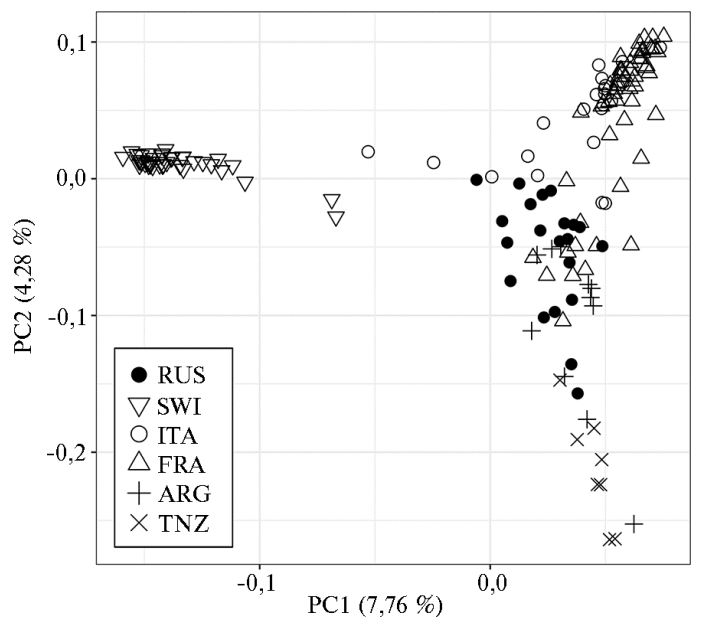

Рис. 1. Результаты РСА-анализа (principal component analysis), проведенного для российской и пяти национальных популяций коз (Capra hircus) зааненской породы на основе SNP-профилей, полученных с использованием ДНК-чипа GoatSNP50 BeadChip (2019-2020 годы). Группы коз зааненской породы: RUS - российская, SWI швейцарская, ITA - итальянская, FRA французская, ARG - аргентинская, TNZ - танзанийская.

В структуре генетической сети, демонстрирующей взаимосвязи российской и пяти национальных популяций коз зааненской породы (рис. 2), было выделено два кластера. Первый включал длинную обособленную ветвь SWI, примыкающий к ней подкластер ITA + FRA и более отдаленную короткую ветвь RUS (на стыке кластеров). Второй кластер был образован 
Для лучшего понимания степени генетической дифференциации между изучаемыми популяциями коз были рассчитаны показатели F $\mathrm{ST}$ и $\mathrm{R}_{\mathrm{ST}}$. Иx значения (табл. 2) оказались максимальными между группами SWI и TNZ $\left(\mathrm{F}_{\mathrm{ST}}=0,109 ; \mathrm{R}_{\mathrm{ST}}=0,374\right)$, а также между SWI и ARG $\left(\mathrm{F}_{\mathrm{ST}}=0,078\right.$; $\left.\mathrm{R}_{\mathrm{ST}}=0,321\right)$. Минимальная дифференциация наблюдалась между ITA и FRA $\left(\mathrm{F}_{\mathrm{ST}}=0,008 ; \mathrm{R}_{\mathrm{ST}}=0,154\right)$.

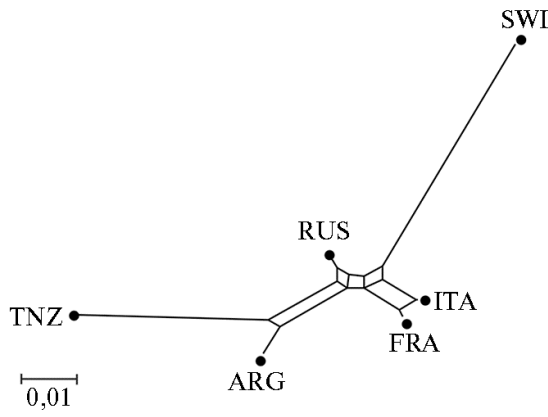

Рис. 2. Генетическая сеть Neighbor Net, построенная на основе попарных значений $\mathrm{F}_{\mathrm{ST}}$ и демонстрирующая взаимосвязи российской и пяти национальных популяций коз (Capra hircus) зааненской породы на основе SNP-профилей, полученных с использованием ДНК-чипа GoatSNP50 BeadChip (2019-2020 годы). Группы коз зааненской породы: RUS - российская, SWI - швейцарская, ITA - итальянская, FRA - французская, ARG - аргентинская, TNZ танзанийская.

При изучении генетических связей RUS с популяциями из других стран было установлено, что минимальные ге-

нетические дистанции наблюдались между RUS и группами FRA и ITA $\left(\mathrm{F}_{\mathrm{ST}}=0,02 ; \mathrm{R}_{\mathrm{ST}}=0,189\right.$ и $\left.\mathrm{F}_{\mathrm{ST}}=0,023 ; \mathrm{R}_{\mathrm{ST}}=0,215\right)$, а наибольшая дифференциация - с группами $\mathrm{TNZ}$ и $\mathrm{SWI}\left(\mathrm{F}_{\mathrm{ST}}=0,054 ; \mathrm{R}_{\mathrm{ST}}=0,311\right.$ и $\left.\mathrm{F}_{\mathrm{ST}}=0,06 ; \mathrm{R}_{\mathrm{ST}}=0,276\right)$.

С целью анализа популяционной структуры изучаемых групп коз мы провели расчет наиболее вероятного числа кластеров (рис. 3, А). Наименьшая ошибка кросс-валидации была идентифицирована при $\mathrm{K}=3$ и составила 0,64445 . При $\mathrm{K}=2$ группа SWI формировала свой собственный обособленный кластер (см. рис. 3, Б). При K = 3 группы ITA и FRA демонстрировали сходную популяционную структуру. Следует отметить, что популяция FRA состояла из неоднородных особей, большая часть которых была высоко консолидирована в своем кластере, а вторая часть (около 30 \% животных) демонстрировала наличие иных геномных компонентов. Группа TNZ формировала свой кластер. Популяции RUS и ARG характеризовались присутствием всех трех выявленных генетических составляющих, при этом RUS сохраняла в своем генофонде наибольшую долю оригинального элемента (SWI).

2. Генетическая дифференциация между российской и пятью национальными популяциями коз (Capra hircus) зааненской породы, оцененная с помощыю показателей $\mathbf{F}_{\mathrm{ST}}$ и $\mathbf{R}_{\mathrm{ST}}$, рассчитанных на основе данных полногеномного генотипирования с использованием ДНК-чипа GoatSNP50 BeadChip (2019-2020 годы)

\begin{tabular}{lllll|l|l|l}
\hline \multicolumn{1}{c|}{ Группа } & RUS & SWI & ITA & FRA & ARG & TNZ \\
\hline RUS & & 0,276 & 0,215 & 0,189 & 0,254 & 0,311 \\
SWI & 0,060 & & 0,275 & 0,276 & 0,321 & 0,374 \\
ITA & 0,023 & 0,059 & & 0,154 & 0,263 & 0,327 \\
FRA & 0,020 & 0,065 & 0,008 & & 0,248 & 0,316 \\
ARG & 0,029 & 0,078 & 0,035 & 0,035 & & 0,318 \\
TNZ & 0,054 & 0,109 & 0,066 & 0,065 & 0,044 &
\end{tabular}

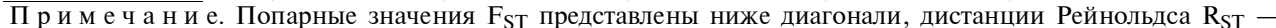
выше диагонали. Группы коз зааненской породы: RUS - российская, SWI - швейцарская, ITA - итальянская, FRA - французская, ARG - аргентинская, TNZ - танзанийская.

Высокопродуктивные, привлекательные для разведения породы сельскохозяйственных животных широко распространены за пределами места своего выведения. В скотоводстве к таким породам относятся голштинская и симментальская, в свиноводстве - ландрас, дюрок и крупная 
белая, в овцеводстве - рамбулье и ромни-марш, в козоводстве безусловный мировой лидер - зааненская порода. В странах-экспортерах начинается активная селекция завезенного генетического материала, в связи с чем оценка идентичности национальных популяций оригинальному генофонду, помимо генетического интереса, имеет прикладное значение, а именно способствует определению общего направления селекции и позволяет вносить возможные корректировки в ее цели (34). Так, сравнительный анализ SNP-профилей симментальского скота немецко-австрийской и российской селекции выявил геномные регионы с высокой частотой встречаемости идентичных гаплотипов, несмотря на определенную разницу в целях селекции (34).
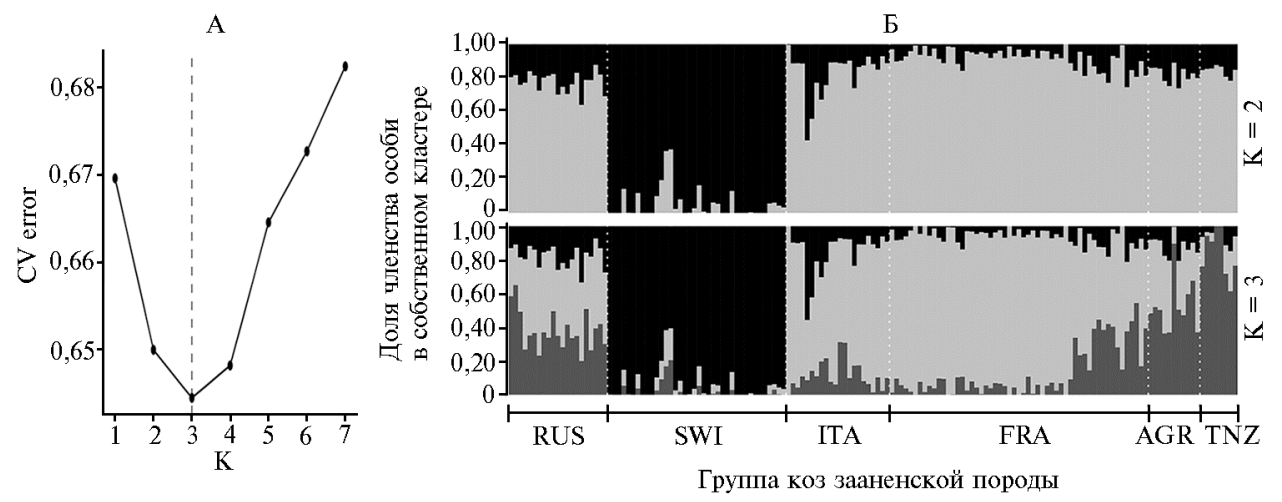

Рис. 3. Сопоставление популяционной структуры и анализ генетической однородности российской и пяти национальных популяций коз (Capra hircus) зааненской породы, проведенные с использованием ДНК-чипа GoatSNP50 BeadChip (2019-2020 годы): А - график, построенный на основе значений ошибок кросс-валидации (CV error), рассчитанных при тестировании количества предковых кластеров (К) от 1 до 7 (пунктирной линией отмечено число кластеров, для которых ошибка кросс-валидации была наименьшей); Б - структура изучаемых популяций при числе кластеров, равном двум и трем. Группы коз зааненской породы: RUS - pocсийская, SWI - швейцарская, ITA - итальянская, FRA - французская, ARG - аргентинская, TNZ - танзанийская.

Зааненская порода была вовлечена в разработку и тестирование ДНК-чипа GoatSNP50BeadChip, поэтому дифференциации между национальными популяциями зааненской породы будут полностью определяться их генетическими различиями и не зависеть от возможных погрешностей, вызванных внутривидовой разницей в полиморфных локусах. Например, ангорская порода коз не входила в инициальный список пород для разработки ДНК-чипа, поэтому S.F. Lashmar с соавт. (35) предварительно оценивали информативность GoatSNP50BeadChip для этой породы.

При сравнении показателей генетического разнообразия, рассчитанных в нашей работе для национальных популяций коз зааненской породы, были отмечены их высокие значения у всех групп, за исключением оригинальной швейцарской. А. Burren с соавт. (36) исследовали генетическое разнообразие у 10 локальных швейцарских пород коз, у которых наблюдаемая гетерозиготность варьировала от 0,369 (аппенцелльская и тоггенбургская) до 0,401 (гризон полосатый и павлин), а аллельное разнообразие - от 1,531 (стифельгесская) до 1,941 (цветная серна). Наблюдаемая гетерозиготность составила 0,385 у альпийской породы, 0,384 - у ламанчской, 0,338 - у нубийской, 0,379 - у зааненской и 0,353 - тоггенбургской породы канадской селекции. Кроме того, у всех перечисленных пород был зафиксирован незначительный недостаток гетерозигот (18). Следует отметить, что показатели $\mathrm{H}_{\mathrm{o}}$ и $\mathrm{Ar}$ у локальных швейцарских коз и 
молочных пород коз канадской селекции скорее соответствовали значениям оригинальной группы SWI и несколько уступали аналогичным показателям у RUS, ITA, FRA, ARG и TNZ.

Подобно зааненской, ангорская порода, берущая начало из Турции, широко распространена во многих странах мира. C. Visser с соавт. (37) использовали Goat SNP50 BeadChip для изучения степени географической изоляции и генетической вариабельности в трех популяциях ангорской породы коз из Южной Африки, Франции и Аргентины. Среди национальных популяций ангорской породы была зафиксирована разница в ожидаемой и наблюдаемой гетерозитности $\left(\mathrm{H}_{\mathrm{e}}=0,371-0,397 ; \mathrm{H}_{\mathrm{o}}=0,365\right.$ $0,414)$, сопоставимая с разницей, вычисленной в нашей работе $\left(\mathrm{H}_{\mathrm{e}}=0,380\right.$ 0,$\left.424 ; \mathrm{H}_{\mathrm{o}}=0,381-0,423\right)$.

Суммируя результаты РСА-анализа и структуры филогенетического дерева, мы выявили четкую дифференциацию между национальными (за исключением более близких ITA и FRA) и оригинальной популяциями коз зааненской породы. C. Visser с соавт. (37) тоже отмечали, что национальные популяции коз ангорской породы очень четко отделяются друг от друга. Значение показателя $\mathrm{F}_{\mathrm{ST}}$ между ангорскими популяциями составило 0,120 , тогда как в нашей работе максимальное значение показателя $\mathrm{F}_{\mathrm{ST}}$ между TNZ и SWI было 0,109. Это может свидетельствовать о том, что популяции зааненской породы еще не так сильно отошли от исходной швейцарской, как ангорские козы.

Интересно, что в соответствии со значением $\mathrm{F}_{\mathrm{ST}}$ наибольшая дифференциация была отмечена между RUS и SWI, тогда как по $\mathrm{R}_{\mathrm{ST}}$ группа RUS оказалась наиболее обособлена от TNZ, что подтверждается положением соответствующих групп на графике PCA. По мнению G. Laval c coавт. (38), вычисление дистанций Рейнольдса - это лучший метод оценки дивергенции между близкородственными группами, что согласуется с полученными нами данными. Кроме того, анализ популяционной структуры подтвердил сохранение геномных компонентов SWI у коз группы RUS.

Таким образом, проведенное полногеномное исследование российской популяции коз зааненской породы показало, что по генетическому и аллельному разнообразию эта группа превосходит оригинальную швейцарскую популяцию, но при этом соответствует группам французской и итальянской селекции. Результаты нашей работы подтвердили, что различные стратегии селекции привели к генетическим различиям между национальными популяциями зааненской породы, включая российскую. Тем не менее российская популяция коз зааненской породы сохраняет геномные компоненты, свойственные исходному генофонду, что, с одной стороны, создает необходимую вариабельность для отбора, с другой - оставляет возможность возвращения к оригинальному типу швейцарской селекции.

\section{ЛИТЕРАТ УРА}

1. Новопашина С.И., Санников М.Ю., Кизилова Е.И. Молочная продуктивность коз разных генотипов. Сб. науч. тр. Всероссийского научно-исследовательского института овцеводства и козоводства, 2017, 1(10): 225-229.

2. Справочник пород и типов сельскохозяйственных жсивотных, разводимых в Российской Федерации /Под ред. И.М. Дунина, А.Г. Данкверта. М., 2013.

3. Devendra C., Haenlein G.F.W. Animals that produce dairy foods | Goat breeds. In: Encyclopedia of dairy sciences (second edition) /J.W. Fuquay (ed.). Academic Press, Amsterdam, 2011: 310-324 (doi: 10.1016/B978-0-12-374407-4.00035-2).

4. Новопашина С.И., Санников М.Ю., Хататаев С.А., Кузьмина Т.Н., Хмелевская Г.Н., Степанова Н.Г., Тихомиров А.И., Маринченко Т.Е. Состояние и перспективные направления улучшения генетического потенциала мелкого рогатого скота: научный аналитический обзор. М., 2019. 
5. Brito L.F., Jafarikia M., Grossi D.A., Kijas J.W., Porto-Neto L.R., Ventura R.V., Salgorzaei M., Schenkel F.S. Characterization of linkage disequilibrium, consistency of gametic phase and admixture in Australian and Canadian goats. BMC Genetics, 2015, 16: 67 (doi: 10.1186/s12863-015-0220-1).

6. da Silva T.G.F., Santos G.C.L., Duarte A.M.C., Turco S.H.N., da Cruz Neto J.F., da Rosa Ferraz Jardim A.M., dos Santos T.S. Black globe temperature from meteorological data and a bioclimatic analysis of the Brazilian northeast for Saanen goats. Journal of Thermal Biology, 2019, 85: 102408 (doi: 10.1016/j.jtherbio.2019.102408).

7. Zamuner F., DiGiacomo K., Cameron A.W.N., Leury B.J. Effects of month of kidding, parity number, and litter size on milk yield of commercial dairy goats in Australia. Journal of Dairy Science, 2020, 103(1): 954-964 (doi: 10.3168/jds.2019-17051).

8. Sun Y., Wang C., Sun X., Guo M. Proteomic analysis of whey proteins in the colostrum and mature milk of Xinong Saanen goats. Journal of Dairy Science, 2020, 103(2): 1164-1174 (doi: 10.3168/jds.2019-17159).

9. Makete G., Aiyegoro O.A., Thantsha M.S. Isolation, identification and screening of potential probiotic bacteria in milk from South African Saanen goats. Probiotics and Antimicrobial Proteins, 2017, 9(3): 246-254 (doi: 10.1007/s12602-016-9247-5).

10. Государственный реестр селекционных достижений, допущенных к использованию. Том 2 «Породы животных» (официальное издание). М., 2019.

11. Ежегодник по племенной работе в овцеводстве и козоводстве в хозяйствах Российской Федерации (2018 год) /Под ред. Т.А. Мороз. М., 2019.

12. Тощев В.К., Мустафина Г.Н. Использование зааненской породы в улучшении молочного козоводства. Аграрная наука, 2012, 5: 27-28.

13. Ajmone-Marsan P., Colli L., Han J.L., Achilli A., Lancioni H., Joost S., Crepaldi P., Pilla F., Stella A., Taberlet P., Boettcher P., Negrini R., Lenstra J.A., Italian Goat Consortium, Econogene Consortium, Globaldiv Consortium. The characterization of goat genetic diversity: towards a genomic approach. Small Ruminant Research, 2014, 121(1): 58-72 (doi: 10.1016/j.smallrumres.2014.06.010).

14. Tosser-Klopp G., Bardou P., Bouchez O., Cabau C., Crooijmans R., Dong Y., DonnadieuTonon C., Eggen A., Heuven H.C.M., Jamli S., Jiken A.J., Klopp C., Lawley C.T., McEwan J., Martin P., Moreno C.R., Mulsant P., Nabihoudine I., Pailhoux E., Palhiere E., Rupp R., Sarry J., Sayre B.L., Tircazes A., Wang J., Wang W., Zhang W., the International Goat Genome Consortium. Design and characterization of a 52k SNP chip for goats. PLoS ONE, 2014, 9(1): e86227 (doi: 10.1371/journal.pone.0086227).

15. Nicoloso L., Bomba L., Colli L., Negrini R., Milanesi M., Mazza R., Sechi T., Frattini S., Talenti A., Coizet B., Chessa S., Marletta D., D'Andrea M., Bordonaro S., Ptak G., Carta A., Pagnacco G., Valentini A., Pilla F., Ajmone-Marsan P., Crepaldi P., the Italian Goat Consortium. Genetic diversity of Italian goat breeds assessed with a medium-density SNP chip. Genetics Selection Evolution, 2015, 47(1): 62 (doi: 10.1186/s12711-015-0140-6).

16. Mdladla K., Dzomba E.F., Huson H.J., Muchadeyi F.C. Population genomic structure and linkage disequilibrium analysis of South African goat breeds using genome-wide SNP data. Animal Genetics, 2016, 47(4): 471-482 (doi: 10.1111/age.12442).

17. Rahmatalla S.A., Arends D., Reissmann M., Ahmed A.S., Wimmers K., Reyer H., Brockmann G.A. Whole genome population genetics analysis of Sudanese goats identifies regions harboring genes associated with major traits. BMC Genetics, 2017, 18: 92 (doi: 10.1186/s12863-0170553-z).

18. Brito L.F., Kijas J.W., Ventura R.V., Sargolzaei M., Porto-Neto L.R., Cánovas A., Feng Z., Jafarikia M., Schenkel F.S. Genetic diversity and signatures of selection in various goat breeds revealed by genome-wide SNP markers. BMC Genomics, 2017, 18: 229 (doi: 10.1186/s12864017-3610-0).

19. Stella A., Nicolazzi E.L., Van Tassell C.P., Rothschild M.F., Colli L., Rosen B.D., Sonstegard T.S., Crepaldi P., Tosser-Klopp G., Joost S., the AdaptMap Consortium. AdaptMap: exploring goat diversity and adaptation. Genetics Selection Evolution, 2018, 50(1): 61 (doi: 10.1186/s12711-018-0427-5).

20. Bertolini F., Cardoso T.F., Marras G., Nicolazzi E.L., Rothschild M.F., Amills M., AdaptMap consortium. Genome-wide patterns of homozygosity provide clues about the population history and adaptation of goats. Genetics Selection Evolution, 2018, 50(1): 59 (doi: 10.1186/s12711-0180424-8).

21. Colli L., Milanesi M., Talenti A., Bertolini F., Chen M., Crisà A., Daly K.G., Del Corvo M., Guldbrandtsen B., Lenstra J.A., Rosen B.D., Vajana E., Catillo G., Joost S., Nicolazzi E.L., Rochat E., Rothschild M.F., Servin B., Sonstegard T.S., Steri R., Van Tassell C.P., AjmoneMarsan P., Crepaldi P., Stella A., the AdaptMap Consortium. Genome-wide SNP profiling of worldwide goat populations reveals strong partitioning of diversity and highlights postdomestication migration routes. Genetics Selection Evolution, 2018, 50(1): 58 (doi: 10.1186/s12711-018-0422-x).

22. Bertolini F., Servin B., Talenti A., Rochat E., Kim E.S., Oget C., Palhière I., Crisà A., Catillo G., Steri R., Amills M., Colli L., Marras G., Milanesi M., Nicolazzi E., Rosen B.D., Van 
Tassell C.P., Guldbrandtsen B., Sonstegard T.S., Tosser-Klopp G., Stella A., Rothschild M.F., Joost S., Crepaldi P., the AdaptMap consortium. Signatures of selection and environmental adaptation across the goat genome post-domestication. Genetics Selection Evolution, 2018, 50(1): 57 (doi: 10.1186/s12711-018-0421-y).

23. Fan J.-B., Oliphant A., Shen R., Kermani B.G., Garcia F., Gunderson K.L., Hansen M., Steemers F., Butler S.L., Deloukas P., Galver L., Hunt S., Mcbride C., Bibikova M., Rubano T., Chen J., Wickham E., Doucet D., Chang W., Campbell D., Zhang B., Kruglyak S., Bentley D., Haas J., Rigault P., Zhou L., Stuelpnagel J., Chee M.S. Highly parallel SNP genotyping. Cold Spring Harb. Symp. Quant. Biol., 2003, 68: 69-78 (doi: 10.1101/sqb.2003.68.69).

24. Chang C.C., Chow C.C., Tellier L.C., Vattikuti S., Purcell S.M., Lee J.J. Second-generation PLINK: rising to the challenge of larger and richer datasets. GigaScience, 2015, 4: s13742-0150047-8 (doi: 10.1186/s13742-015-0047-8).

25. Colli L., Milanesi M., Talenti A., Bertolini F., Chen M., Crisà A., Daly K., Del Corvo M., Guldbrandtsen B., Lenstra J.A., Rosen B.D., Vajana E., Catillo G., Joost S., Nicolazzi E.L., Rochat E., Rothschild M.F., Servin B., Sonstegard T.S., Steri R., Van Tassell C.P., AjmoneMarsan P., Crepaldi P., Stella A., AdaptMap Consortium. Data from: Signatures of selection and environmental adaptation across the goat genome post-domestication, Dryad, Dataset, 2018 (doi: 10.5061/dryad.v8g21 pt).

26. Weir B.S., Cockerham C.C. Estimating F-statistics for the analysis of population structure. Evolution, 1984, 38(6): 1358-1370 (doi: 10.2307/2408641).

27. Reynolds J., Weir B.S., Cockerham C.C. Estimation of the coancestry coefficient: basis for a short-term genetic distance. Genetics, 1983, 105(3): 767-779.

28. Keenan K., McGinnity P., Cross T.F., Crozier W.W., Prodöhl P.A. diveRsity: an R package for the estimation of population genetics parameters and their associated errors. Methods in Ecology and Evolution, 2013, 4(8): 782-788 (doi: 10.1111/2041-210X.12067).

29. Wickham H. ggplot2: elegant graphics for data analysis. Springer-Verlag, NY, 2009.

30. Huson D.H., Bryant D. Application of phylogenetic networks in evolutionary studies. Molecular Biology and Evolution, 2006, 23(2): 254-267 (doi: 10.1093/molbev/msj030).

31. Alexander D.H., Novembre J., Lange K. Fast model-based estimation of ancestry in unrelated individuals. Genome Research, 2009, 19(9): 1655-1664 (doi: 10.1101/gr.094052.109).

32. Francis R.M. pophelper: An R package and web app to analyse and visualise population structure. Molecular Ecology Resources, 2017, 17(1): 27-32 (doi: 10.1111/1755-0998.12509).

33. R Core Team (2018). $R$ : a language and environment for statistical computing. $R$ foundation for statistical computing, Vienna, Austria. Режим доступа: https://www.R-project.org/. Без даты.

34. Mészáros G., Fornara M.S., Reyer H., Wimmers K., Sölkner J., Brem G., Sermyagin A.A., Zinovieva N.A. Elevated haplotypes frequencies reveal similarities for selection signatures in Western and Russian Simmental populations. Journal of Central European Agriculture, 2019, 20(1): 1-11 (doi: 10.5513/JCEA01/20.1.2412).

35. Lashmar S.F., Visser C., Van Marle-Köster E. Validation of the 50k Illumina goat SNP chip in the South African Angora goat (short communication). South African Journal of Animal Science, 2015, 45(1): 56-59 (doi: 10.4314/sajas.v45i1.7).

36. Burren A., Neuditschko M., Signer-Hasler H., Frischknecht M., Reber I., Menzi F., Drögemüller C., Flury C. Genetic diversity analyses reveal first insights into breed-specific selection signatures within Swiss goat breeds. Animal Genetics, 2016, 47(6): 727-739 (doi: 10.1111/age.12476).

37. Visser C., Lashmar S.F., Van Marle-Köster E., Poli M.A., Allain D. Genetic diversity and population structure in South African, French and Argentinian Angora goats from genome-wide SNP data. PLoS ONE, 2016, 11(5): e0154353 (doi: 10.1371/journal.pone.0154353).

38. Laval G., SanCristobal M., Chevalet C. Measuring genetic distances between breeds: use of some distances in various short term evolution models. Genetics Selection Evolution, 2002, 34(4): 481-507 (doi: 10.1051/gse:2002019).

ІФГБНУ ФНЦ животноводства -

ВИЖ им. академика Л.К. Эрнста,

142132 Россия, Московская обл., г.о. Подольск, пос. Дубровицы, 60, e-mail: horarka@yandex.ru $₫$, asnd@mail.ru, margaretfornara@gmail.com, alex_sermyagin85@mail.ru,n_zinovieva@mail.ru;

2Institute of Genome Biology,

Leibniz, Institute for Farm Animal Biology (FBN),

Mecklenburg-Vorpommern, 18196 Dummerstorf, Germany,

e-mail: reyer@fbn-dummerstorf.de, wimmers@fbn-dummerstorf.de;

3 Institut für Tierzucht und Genetik, University of Veterinary Medicine (VMU),

Veterinärplatz, A-1210, Vienna, Austria,

e-mail: gottfried.brem@agrobiogen.de
Поступила в редакцию 26 февраля 2020 года 


\title{
THE GENOMIC ARCHITECTURE OF THE RUSSIAN POPULATION OF SAANEN GOATS IN COMPARISON WITH WORLDWIDE SAANEN GENE POOL FROM FIVE COUNTRIES
}

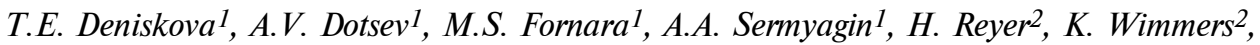 \\ G. Brem ${ }^{1,3}$, N.A. Zinovieva ${ }^{1}$
}

\begin{abstract}
${ }^{1}$ Ernst Federal Science Center for Animal Husbandry, 60, pos. Dubrovitsy, Podolsk District, Moscow Province, 142132 Russia, e-mail horarka@yandex.ru ( $₫$ corresponding author), asnd@mail.ru, margaretfornara@gmail.com, alex_sermyagin85@mail.ru,n_zinovieva@mail.ru;

2Institute of Genome Biology, Leibniz Institute for Farm Animal Biology (FBN), Mecklenburg-Vorpommern, 18196 Dummerstorf, Germany, e-mail reyer@fbn-dummerstorf.de, wimmers@fbn-dummerstorf.de;

${ }^{3}$ Institut für Tierzucht und Genetik, University of Veterinary Medicine (VMU), Veterinärplatz, A-1210, Vienna, Austria, e-mail gottfried.brem@agrobiogen.de

ORCID:

Deniskova T.E. orcid.org/0000-0002-5809-1262

Dotsev A.V. orcid.org/0000-0003-3418-2511

Fornara M.S. orcid.org/0000-0002-8844-177X

Sermyagin A.A. orcid.org/0000-0002-1799-601

Reyer H. orcid.org/0000-0001-6470-0434

Wimmers K. orcid.org/0000-0002-9523-6790

Brem G. orcid.org/0000-0002-7522-0708

The authors declare no conflict of interests

Zinovieva N.A. orcid.org/0000-0003-4017-6863

Acknowledgements:

During the research, the equipment of the Center for Biological Resources and Bioengineering of Agricultural Animals (Ernst Federal Science Center for Animal Husbandry) was used.

Supported financially by the Russian Foundation for Basic Research, project No. 18-316-20006

Received February 26, 2020

doi: 10.15389 /agrobiology.2020.2.285eng
\end{abstract}

\section{Abstract}

The Saanen goat breed is valued for its high milk productivity and good adaptive qualities, which contributed to its worldwide distribution outside Switzerland. In Russia, the Saanen is a popular breed that had been officially recommended for breeding and had a pedigree status. Breeding in local environments as well as regional specifics of the used breeding strategies can lead to a significant change in the allele pool of breeds, and therefore, it is relevant to conduct genomic studies of national populations of world breeds to establish their current genetic status. Here, for the first time we presented the results of whole-genome analysis of the Russian population of goats of the Saanen breed in comparative aspect with the original (Switzerland) and the world gene pool of the Saanen breed, represented by four countries. The aim of our work was to assess genetic diversity and to study population structure of the Saanen goats of Russian selection in comparison with representatives of this breed from five different countries (Switzerland, Italy, France, Argentina and Tanzania) whose whole-genome SNP-profiles were obtained from the database of the AdaptMap project. The studies were conducted on 21 goats of the Saanen breed (RUS), bred in one of the Russian breeding farms, in 2019-2020. DNA was extracted from the selected ear fragments using DNA Extran-2 kits (Syntol CJSC, Russia). Genotyping was performed using a GoatSNP50 BeadChip DNA chip (Illumina, Inc., USA) containing 53347 SNPs and providing coverage of the average interval between SNPs in $40 \mathrm{~kb}$. To assess the genetic diversity and to perform comparative analysis of the Russian goat population with the representatives goats of this breed from five different countries, we used SNP-profiles of the Saanen goats bred in Switzerland (SWI, $n=38$ ), Italy (ITA, $n=22$ ), France (FRA, $n=55$ ), Argentina (ARG, $n=11$ ) and Tanzania (TNZ, $n=8$ ), which were downloaded from the publicly available digital data repository Dryad and generated in within the AdaptMap project. The Swiss population of the Saanen breed was assumed as a sample of the original gene pool. Bioinformatic processing and visualization of whole-genome genotyping data was performed in the PLINK 1.90, Admixture 1.3, SplitsTree 4.14.5 software, in R packages "diveRsity" and "pophelper". The observed heterozygosity varied from 0.381 in SWI to 0.423 in FRA and was high in RUS (Ho $=0.418$ ). In SWI, ITA, FRA populations the values of the inbreeding coefficient were close to zero level; RUS, ARG, and TNZ showed heterozygote deficiencies, which were $1.5 \%, 8.9$, and $6.0 \%$, respectively. Allelic richness was maximal in ARG, RUS, and FRA $(\mathrm{Ar} \geq 1.979)$ and minimal in SWI $(\mathrm{Ar}=1.934)$. The Principal component analysis and the phylogenetic tree showed a clear differentiation between the national and original populations of the Saanen breed. Analysis of population structure demonstrated the presence of the genetic component of the SWI cluster in goats from the RUS group. RUS had the smallest genetic distances with FRA $\left(\mathrm{F}_{\mathrm{ST}}=0.02 ; \mathrm{R}_{\mathrm{ST}}=0.189\right)$ and ITA $\left(\mathrm{F}_{\mathrm{ST}}=0.023 ; \mathrm{R}_{\mathrm{ST}}=0.215\right)$; and RUS was highly differentiated from TNZ $\left(\mathrm{F}_{\mathrm{ST}}=0.054 ; \mathrm{R}_{\mathrm{ST}}=0.311\right)$ and $\mathrm{SWI}\left(\mathrm{F}_{\mathrm{ST}}=0.06\right.$; $\mathrm{R}_{\mathrm{ST}}=0.276$ ). Thus, different selection strategies resulted in genetic differences between the national goat populations of the Saanen breed. However, genomic components of the original gene pool are still present in the Russian goat population of the Saanen breed. AdaptMap.

Keywords: Saanen breed, domestic goats, SNP markers, DNA chips, genetic diversity, 